\title{
INCREASE OF MOBILITY OF IONS IN LI-ION BATTERIES BY ULTRATHIN PHONON COATINGS OF ELECTRODES
}

\author{
D. Lj. Mirjanic ${ }^{1, *}$, J. P. Šetrajčić ${ }^{1,2}$, S. S. Pelemis $\breve{s}^{3}$, S. Armaković ${ }^{2}$ \\ ${ }^{1}$ The Academy of Sciences and Arts of the Republic of Srpska, \\ 78000 Banja Luka, Bana Lazarevića 1, Republic of Srpska, B\&H \\ ${ }^{2}$ University of Novi Sad, Faculty of Sciences, Department of Physics, \\ 21000 Novi Sad, Trg Dositeja Obradovića 4, Vojvodina, Serbia \\ ${ }^{3}$ University of Eastern Sarajevo, Faculty of Technology, Karakaj bb, \\ 75400 Zvornik, Republic of Srpska, B\&H
}

\begin{abstract}
This paper presents the results of research of behavior of phonon subsystem in ultrathin coatings that are applied on electrodes in Li-ion batteries and that increase the efficiency of ion transport. Using the method of Green functions it was demonstrated that in ultrathin films, increased mechanical oscillating of crystalline lattice and forming of standing waves occur, while, thermal capacitiveness and conduction of the overall coating decreases. With their increased oscillating, phonons release the ions captured on and within electrodes, and thus influence an increase in efficiency of ion conductivity.

Keywords: ion conductivity, Li-ion batteries, ultrathin films, phonons, heat capacity.
\end{abstract}

\section{INTRODUCTION}

In this paper we analyze nanostructure materials designed for energy conversion and energy storing. Li-ion batteries could fulfill the goals set very ambitiously having in mind their specific energy density [1] in terms of volume (about $300 \mathrm{Wh} / \mathrm{m}^{3}$ ) and weight (about $130 \mathrm{Wh} / \mathrm{kg}$ ). This type of battery has a number of advantages over other battery types, including high capacity, high energy density and operating voltage. Conversely, the power density cannot provide for all the demands of the users. Unfortunately, this bigger surface does not necessarily lead to the expected results. Namely, something that is equally important or even more important is how to design a microstructure of electrode composite available for Li-ions.

In that sense, nanostructure materials play an important role in Li-ion batteries as well. In some cases, nanostructure materials, due to their special morphology, demonstrate unexpected electric-chemical behavior. Nonetheless, in most cases, when nanostructure materials are used in Li-ion batteries, a decrease of size of up to 10-20 nm only leads to shorter diffusion length and bigger surface of Li incorporation in hard matrix. This problem can in principle be solved by use of mezzo-porous and macro-porous active materials with thickness of walls of about 10
$-20 \mathrm{~nm}$ [2]. These materials may solve ion contact between active materials and electrolytes. An equal deal of attention should be paid to achieving good electronic conduction.

On the whole, in order for a Li-ion battery to function, parallel conduction by electrons and ions is necessary, whereas for high-power batteries such conduction is even essential. We will propose a number of nano-architectures of special design, with each given material requiring a special design; such a design cannot be expanded to other types of active materials.

All battery technologies experience kinetic problems related to solid-state diffusion of $\mathrm{Li}$ in electrodes, and in some cases related to the conductivity of electrolytes and the quality of interfaces. In order to improve kinetics, architectures of nanostructure electrodes are usually proposed, although their design is not trivial [2]. They are made in the form of ultrathin film layers, i.e. coatings.

The contact between electrodes should provide mechanical cohesion during the operation of the battery but can also influence the properties of electrodes across the surface modification. Using atomic force microscopy (ACM), surface structures were studied in three binders: polyvinylidene fluoride (PVDF), carboxyl methyl cellulose (CMC) and gelatin. An attempt was to find a correlation between 
the observed structures and determine electro-chemical charge-discharge characteristics. Bonding properties of gelatin, absorbed at various $\mathrm{pH}$ values were measured. Although gelatin has the best properties at $\mathrm{pH}$ of about 9 , the smallest polarization is determined at $\mathrm{pH}$ 12. Both properties are explained based on the observed gelatin structuring as a function of $\mathrm{pH}$ value. Gelatin is also used as a surface agent that determines the distribution of nanometer carbon black particles around the micrometer-sized cathodic active particles. It is believed that it is this drop in resistance that significantly improves performances of various cathode materials, such as $\mathrm{LiMn}_{2} \mathrm{O}_{4}$ and $\mathrm{LiCoO}_{2}[3]$.

Lithium-iron-phosphate $\left(\mathrm{LiFePO}_{4}\right)$ is one of the most promising cathode materials for Li-ion bat- teries due to its high capacity, low price and ecological nature. Improvement of inherent electronic conductivity may be achieved through a number of methods, including the method of carbon coating, ion supervalent doping at the place of $\mathrm{Li}$ and nano-interconnection of electronically conductive materials. By this method, an equally doped material with electronic conductivity as high as $4,8 \cdot 10^{-2} \mathrm{~S} / \mathrm{cm}$ can be obtained. However, as it was expected, improved electronic conductivity does not seem to have improved the performances of $\mathrm{LiFePO}_{4}$. Based on these results, it seems that besides electro-conductivity, other properties of the material such as ion conductivity and phase transformations may also have a strong influence on the efficiency rate [4].

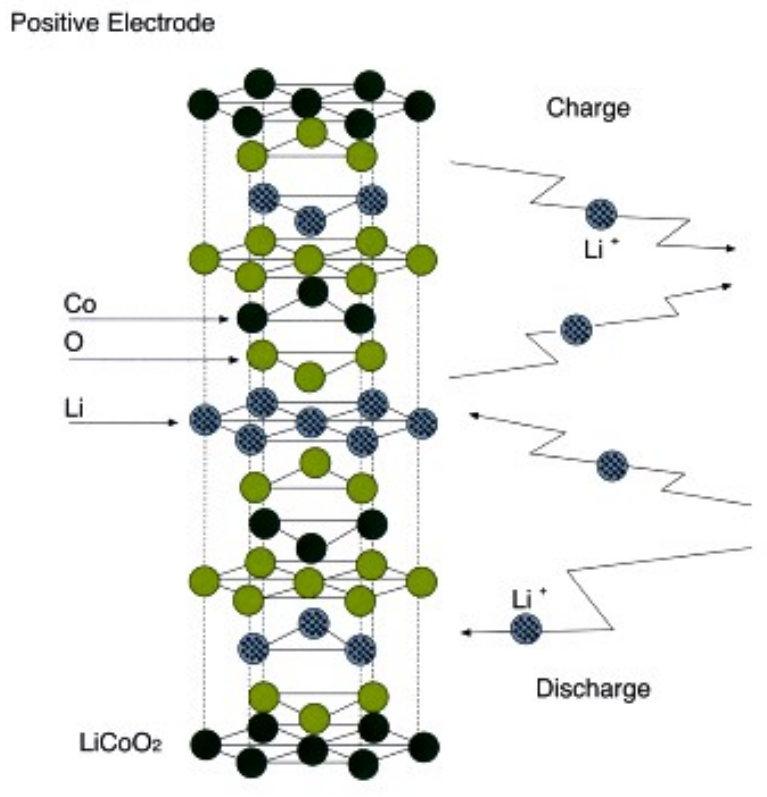

Figure 1. Structure of Li-ion battery
$\mathrm{Li}_{1-\mathrm{x}} \mathrm{CoO}_{2}$ is the most available cathode material commercially. Unfortunately, practical application of $\mathrm{Li}_{1-\mathrm{x}} \mathrm{CoO}_{2}$ is limited by its instability. It fails quickly at potentials higher than 4,2-4,3 V. With the disintegration of cobalt, structural changes and oxidative electrolyte decomposition, dramatic increase in capacities fades at higher potentials. These instabilities can be solved by a coating of $\mathrm{LiCoO}_{2}$ powder with metal oxide coatings from 10 to 100 nm thick... The examples of metal oxides that were investigated include: $\mathrm{Al}_{2} \mathrm{O}_{3}, \mathrm{ZrO}_{2}, \mathrm{ZnO}, \mathrm{SiO}_{2}$, and $\mathrm{TiO}_{2}$. Metal phosphates, e.g. $\mathrm{AlPO}_{4}$ and metal fluorides e.g. $\mathrm{AlF}_{3}$ have also been analyzed as coatings. Most coating methods are based on techniques such as sol-gel method. Additionally, wet chemical coa- ting methods require high quantities of solution and precursors. Post-thermal treatment is necessary even after sol-gel coating. Conversely, the Atomic Layer Deposition Method (ALD) is a gas-phase method of thin films with the use of sequential, self-limited surface reactions.

ALD requires only a minimum quantity of precursors and ALD coatings are compatible and provide control of atomic thickness. ALD could be a promising alternative manner for coating electrode materials for LIBs [5].

In the most general case, the efficiency of electrode may be brought in direct connection with the passage of ions. In other words, the bigger the passage of ions the bigger efficiency of electrode. A 
question is readily asked how is it that the increased efficiency of electrodes is a consequence of the presence of coating, because the coating essentially represents an additional „barrier“ for the passage of ions. We believe that the answer lies in mechanical properties of coating. Namely, it is possible to draw full analogy of thin electrode coating with ultra-thin films. After drawing the analogy, the only thing that should be examined is a phonon sub-system of ultrathin films, which was done further in the paper, as this is the system responsible for mechanical properties.

\section{ULTRATHIN LAYERS - COATINGS}

Ultrathin films [6-9] are the structures with disrupted symmetry in one direction. Such structures can be analyzed via a single-particle wave function, however such an approach is not self-contained, because statistical formulas have to be „borrowed“ in order to calculate the statistical mean values. The only complete method is the method of Green's functions as it gives both dynamic and statistical characteristics of the system.

It should be noted that there are still many unanswered questions considering the application of Green's functions to the structures with disrupted symmetry [10-13]. The reasons for this lie in the fact that in the direction of symmetry disruption, Green's function does not depend on the difference of spatial indices, but on each of them separately. This problem is solved in some papers by examining the Green's function diagonally with space indices in the direction of symmetry disruption, or it is assumed that the Green's function depends on the difference of spatial coordinates in the direction of symmetry disruption, and then the corrections are made in its Fourier-image, which is impulse-dependant, based on the fact that the impulse component is not sustainable in the direction of symmetry.

None of the mentioned approaches reproduces the basic characteristic of the system with disrupted symmetry, or only reproduces it partly; this characteristic is the dependence of physical characteristics of a disrupted symmetry structure upon the spatial coordinates. The purpose of this paper is to formulate the correct methodology of computation of Green's functions [14-15] in disrupted symmetry structures and to apply it to the analysis of mechanical oscillations in ultrathin film.

\section{PHONONS IN CRYSTALLINE FILMS}

Crystalline films are confined crystalline structures [16-18] in which translational symmetry is broken along the direction perpendicular to the film (z-direction, Fig.2).

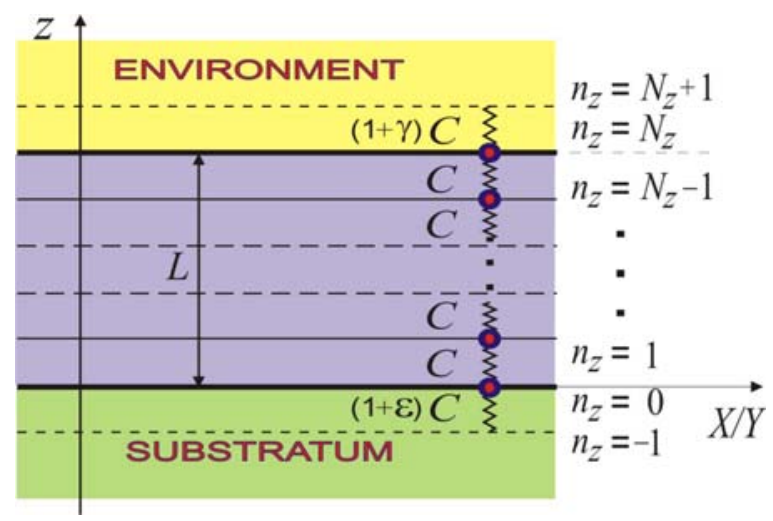

Figure 2. The crystalline nanofilm model-structure

In this paper we observe an ideal ultrathin film of simple cubic crystalline structure, made on the substrate with the use of some appropriate technological process (deposition, sputtering, etc.), whose basic crystallographic parameters are [4-6]: $a_{x}=a_{y}=a_{z} \equiv a ; N_{x, y} \sim 10^{8}>>N_{z} \sim 10$.

Allowing for all this, we are able to say the following about the described model structure:

- torsion Hooke's elastic constants $C^{\alpha \beta}$ are negligible relative to the straining constants $C^{\alpha \alpha} \equiv C^{\alpha}$ : $C_{\vec{n}, \vec{m}}^{\alpha,}=C_{\vec{n}, \vec{n} \pm \vec{\lambda}}^{\alpha}=C_{\vec{n}, \vec{n} \pm \vec{\lambda}}=C_{n_{z}, n_{z} \pm 1}=C_{n_{z} \pm 1}$

- crystalline film has two infinite boundaries parallel to the XY-planes for $z=0$ and $z=L$, while along $z$-direction it has finite thickness ( $L$ $=N_{z} a$; along $z$-direction there are $N_{z}+1$ atoms);

It is considered that there is an interaction between atoms in boundary layers of film and external areas (substrate and e.g. air), disregarding that along $z$-direction there are no atoms of film; however, boundary atoms are coupled through changed Hooke's forces with the atoms of external environment. In accordance with these conditions, elastic constants which describe the interaction between atoms of boundary surfaces and external environment are modified with appropriate coefficients $\varepsilon$ and $\gamma(\varepsilon, \gamma \leq 1): C_{-1}=(1+\varepsilon) C ; \quad C_{N_{z}+1}=(1+\gamma) C$.

With respect to defined model and regarding the fact that layers with $n_{z} \leq-1$ and $n_{z} \geq N_{z}+1$ are not present: $\quad u_{\alpha ; n_{x}, n_{y, j}}=0 ; \quad-1 \geq j \wedge j \geq N_{z}+1$, Hamiltonian of the phonon subsystem for described nanocrystalline film - written in the nearest neighbors approximations $[6,7]-$ is: 


$$
\begin{aligned}
H=\sum_{\alpha ; \vec{n}} & \frac{p_{\alpha ; \vec{n}}^{2}}{2 M}+\sum_{\alpha, n_{x}, n_{y}} \sum_{n_{z}=-1}^{N_{z}+1} \frac{C_{n_{z}}^{\alpha}}{4}\left[\left(u_{\alpha ; n_{x}+1, n_{y}, n_{z}}-u_{\alpha ; n_{x}, n_{y}, n_{z}}\right)^{2}+\left(u_{\alpha ; n_{x}-1, n_{y}, n_{z}}-u_{\alpha ; n_{x}, n_{y}, n_{z}}\right)^{2}+\right. \\
& +\left(u_{\alpha ; n_{x}, n_{y}+1, n_{z}}-u_{\alpha ; n_{x}, n_{y}, n_{z}}\right)^{2}+\left(u_{\alpha ; n_{x}, n_{y}-1, n_{z}}-u_{\alpha ; n_{x}, n_{y}, n_{z}}\right)^{2}+ \\
& \left.+\left(u_{\alpha ; n_{x}, n_{y}, n_{z}+1}-u_{\alpha ; n_{x}, n_{y}, n_{z}}\right)^{2}+\left(u_{\alpha ; n_{x}, n_{y}, n_{z}-1}-u_{\alpha ; n_{x}, n_{y}, n_{z}}\right)^{2}\right],
\end{aligned}
$$

Energy spectra and states will be determined we observe two-time commutator Green's function by using Green's function method. For that purpose $[6,7,20]$ with the corresponding equation of motion:

$$
\begin{gathered}
G_{\vec{n}, \vec{m}}^{\alpha}\left(t-t^{\prime}\right) \equiv\left\langle\left\langle u_{\alpha ; \vec{n}}(t) \mid u_{\alpha ; \vec{m}}\left(t^{\prime}\right)\right\rangle\right\rangle=\Theta\left(t-t^{\prime}\right)\left\langle\left[u_{\alpha ; \vec{n}}(t), u_{\alpha ; \vec{m}}\left(t^{\prime}\right)\right]\right\rangle_{0} . \\
M \frac{d^{2}}{d t^{2}} G_{\vec{n}, \vec{m}}^{\alpha}\left(t-t^{\prime}\right)=-i \hbar \delta_{\vec{n}, \vec{m}} \delta\left(t-t^{\prime}\right)+\frac{\Theta\left(t-t^{\prime}\right)}{i \hbar}\left\langle\left[\left[p_{\alpha ; \vec{n}}(t), \quad H(t)\right], u_{\alpha ; \vec{m}}\left(t^{\prime}\right)\right]\right\rangle_{0} .
\end{gathered}
$$

By calculating corresponding commutators and using the partial spatial Fourier-transform (because the translational symmetry has been disturbed only along the $z$-direction) we obtain the system of $N_{z}+1$ homogeneous algebraic-difference equations [20]:

$G_{n_{z}-1, m_{z}}^{\alpha}+\rho_{\vec{k}}^{\alpha} G_{n_{z}, m_{z}}^{\alpha}+G_{n_{z}+1, m_{z}}^{\alpha}=K \delta_{n_{z}, m_{z}}$

where:

$$
\begin{aligned}
& G_{n_{z}, m_{z}}^{\alpha} \equiv G_{n_{z}, m_{z}}^{\alpha}\left(k_{x} k_{y} ; \omega\right) ; K \equiv \frac{i \hbar}{2 \pi C_{\alpha}} ; \\
& k \equiv \sqrt{k_{x}^{2}+k_{y}^{2}},
\end{aligned}
$$

while the determinant of that system of equations is:

$$
D_{N_{z}+1}(\rho)=\left|\begin{array}{ccccccc}
\rho-\varepsilon & 1 & 0 & \ldots & 0 & 0 & 0 \\
1 & \rho & 1 & \ldots & 0 & 0 & 0 \\
0 & 1 & \rho & \ldots & 0 & 0 & 0 \\
. & . & . & \ddots & . & . & . \\
0 & 0 & 0 & \ldots & \rho & 1 & 0 \\
0 & 0 & 0 & \ldots & 1 & \rho & 1 \\
0 & 0 & 0 & \ldots & 0 & 1 & \rho-\gamma
\end{array}\right|_{N_{z}+1}
$$

where:

$$
\rho_{k}^{\alpha}=\frac{\omega^{2}}{\Omega_{\alpha}^{2}}-4 \sin ^{2} \frac{a k_{x}}{2}-4 \sin ^{2} \frac{a k_{y}}{2}-2 \equiv \rho
$$

\section{PHONON SPECTRA IN CRYSTALLINE FILMS}

Finding of spectra of the allowed phonon energies amounts to determining the zeroes of the determinant (4), that is, to solving of the equality:

$$
\begin{aligned}
& D_{N_{z}+1}(\rho ; \varepsilon, \gamma) \equiv 0 \Rightarrow \rho=\rho_{v}(\varepsilon, \gamma) \\
& v=1,2,3, \ldots N_{z}+1 .
\end{aligned}
$$

This task in general is not analytically solvable (it can be solved numerically with given parameters $\varepsilon, \gamma$ and $N_{z}$ ). When $\varepsilon=\gamma=0$ (model of the loose surfaces [1,2]) there is an analytical solution:

$D_{N_{z}+1}(\rho)=\rho P_{N_{z}}(\rho)-P_{N_{z}-1}(\rho) \equiv P_{N_{z}+1}(\rho)$. (7)

when the determinant (4) of the system of equations (3) is expressed directly through the characteristic Chebyshev's polynomials of order $N_{z}$. In this case we obtain an expression which gives us the phonon dispersion law in ultrathin and structurally undeformed crystalline nanofilm:

$$
\begin{aligned}
& \mathcal{E}_{v}^{\alpha}(\vec{k})=2 \sqrt{R_{k}+S(v)} ; \\
& R_{k} \equiv \sin ^{2} \frac{a k_{x}}{2}+\sin ^{2} \frac{a k_{y}}{2} ; \\
& S(v) \equiv \sin ^{2} \frac{a k_{z}(v)}{2},
\end{aligned}
$$

where $k_{x}$ and $k_{y}$ are virtually continual within the interval $[0, \pi / a]$, and $k_{z}$ has distinctly discrete values:

$$
k_{z}(v)=\frac{\pi}{a} \frac{v}{N_{z}+2} ; \quad v=1,2,3, \ldots, N_{z}+1 .
$$

The dispersion law (8) is presented graphically in Fig.3, with broken lines representing unbounded structures - where the spectra are continual, and full lines represent thin film, which is discrete.

Analyzing the expression (8) it can further be observed that: 


$$
\begin{aligned}
& k_{x}^{\min }=k_{y}^{\min }=0 ; k_{z}^{\min } \equiv \\
& \equiv k_{z}(v=1)=\frac{\pi}{a} \frac{1}{N_{z}+2}>0,
\end{aligned}
$$

since we interfere in nano-thin film $\left(N_{z}<<\left(N_{x}, N_{y}\right)\right)$ and:

$$
\begin{aligned}
& k_{z}^{\max }==k_{y}^{\max }=\frac{\pi}{a} ; \\
& k_{z}^{\max } \equiv k_{z}\left(v=N_{z}+1\right)=\frac{\pi}{a} \frac{N_{z}+1}{N_{z}+2}<\frac{\pi}{a} .
\end{aligned}
$$

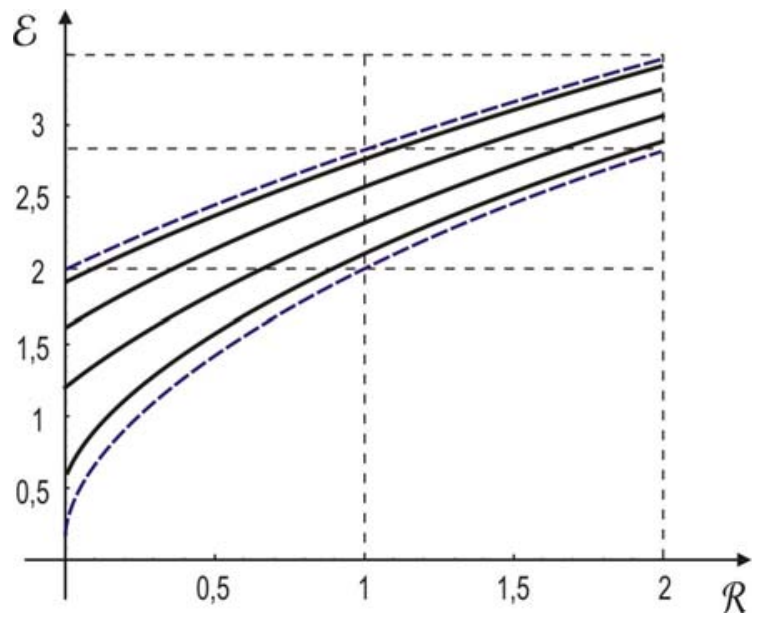

Figure 3. The phonon energy spectra in nanofilm

Between minimal and maximum values for $k_{z}$, and thus for $\varepsilon_{v}(\vec{k})$, there are $N_{z}-1$ discrete values. This means that phonons in thin films have a lower energy gap:

$$
\Delta \equiv \Delta_{\min }=\mathcal{E}_{1}^{\alpha}\left(k_{x}=k_{y}=0, k_{z}=k_{z}^{\min }\right)=2 \sin \left[\frac{\pi}{2\left(N_{z}+2\right)}\right]
$$

as well as an upper energy gap, which is of less physical interest.

In Fig. 3 we can see the gaps and energy discreteness (for thin film) which are sole consequences of existence of spatial boundaries. What is important to remark and to underline is that the differences between bulk and thin film structures manifest themselves only for extremely thin nanofilm. If the number of crystalline planes exceeds ten, quantification of energy gaps and spectra discreteness disappear, which is in accordance with the known facts.

\section{PHONON STATES IN THIN FILM}

In the above-mentioned case of observed nanofilm, for the number of allowed values of $\vec{k}$ per volume unit of $\vec{k}$-space, the following adjusted expression is applicable [6,7]:

$$
D_{f}(\omega)=\frac{N_{z} N_{y}\left(N_{z}+1\right)}{\Delta k_{x} \Delta k_{y} \Delta k_{z}} \int_{0}^{2 \pi} d \varphi \int_{k_{z}^{\min }}^{k_{z}^{D}} d k_{z} \int_{0}^{k_{\max }} k d k \delta(\omega-\omega(k))
$$

where:

$$
k_{z}^{\min }=\frac{\pi}{a} \frac{1}{N_{z}+2}, \quad k_{\max } \equiv k_{x y}^{D}=\sqrt{\frac{2}{3} \sqrt[3]{6 \pi^{2}}} \quad \text { and }
$$

$k_{z}^{D}<k_{z}^{\max }=\frac{\pi}{a} \frac{N_{z}+1}{N_{z}+2} \quad$ is $\quad$ still indeterminate maximum value of $z$-component of wave vector in film structures. By using the dispersion law (8) for small values of wave vector in form: $\omega(k)=\Omega q$, where $q=\sqrt{a^{2} k^{2}+\Delta^{2}}$ and by applying the normalization condition (according to which the total number of phonon states is equal to the number of atoms) we obtain:

$$
N_{f}=\int_{0}^{\omega_{D}} D_{f}(\omega) d \omega=\frac{N_{f}}{\left(\frac{2 \pi}{a}\right)^{3}} \frac{2 \pi}{\Omega^{2} a^{2}} \int_{k_{z}^{\min }}^{k_{z}^{D}} \frac{\omega_{D}^{2}(k)}{2} d k_{z}
$$

where $\omega_{D}(\vec{k}) \equiv a \Omega \sqrt{\left(k_{x y}^{D}\right)^{2}+k_{z}^{2}}$. After solving the corresponding integrals, the expressions for Debye frequency and corresponding component of wave vector of observed nanofilm are obtained:

$$
\begin{aligned}
& \omega_{D}^{f}=\Omega \sqrt{8 \pi \frac{N_{z}^{f}+2}{N_{z}^{f}}} ; \\
& k_{D}^{f}=\frac{1}{a} \sqrt{8 \pi \frac{N_{z}^{f}+2}{N_{z}^{f}}} ; \\
& k_{z}^{D}=\frac{\pi}{\sqrt{3}} \frac{\sqrt{N_{z}^{2}+3 N_{z}+3}}{N_{z}+2}
\end{aligned}
$$

whence it can be seen that: $k_{z}^{D}<k_{z}^{\max }$, i.e. $\frac{k_{z}^{D}}{k_{z}^{\max }}=\frac{\sqrt{N_{z}^{2}+3 N_{z}+3}}{\sqrt{3} N_{z}+1}$. Looking for the density of phonon states ratio in ideal (unbound) and film structures, exactly on Debye frequencies:

$$
\omega_{D}^{f}=\Omega \sqrt{8 \pi \frac{N_{z}^{f}+2}{N_{z}^{f}}} ;
$$




$$
\begin{aligned}
& k_{D}^{f}=\frac{1}{a} \sqrt{8 \pi \frac{N_{z}^{f}+2}{N_{z}^{f}}} ; \\
& k_{z}^{D}=\frac{\pi}{\sqrt{3}} \frac{\sqrt{N_{z}^{2}+3 N_{z}+3}}{N_{z}+2}
\end{aligned}
$$

it follows that the population of phonons in nanofilm:

$$
\frac{D_{f}\left(\omega_{D}^{f}\right)}{D_{i}\left(\omega_{D}^{i}\right)}=\frac{\pi^{1 / 6} \sqrt{2}}{\sqrt[3]{36}} \frac{N_{z}^{f}}{N_{z}^{i}} \frac{N_{z}^{f}+1}{N_{z}^{i}+2} \sqrt{\frac{N_{z}^{f}+2}{N_{z}^{f}}}
$$

is much more scarce than in the corresponding ideal structure, with the assumption that the sound velocity is the same in both mediums $v_{i} \approx v_{f}$. Similarly, the Debye frequencies ratio in both systems observed can be found to be:

$$
\frac{\omega_{D}^{f}}{\omega_{D}^{i}}=\frac{\sqrt{8 \pi}}{\sqrt[3]{6 \pi^{2}}} \sqrt{\frac{N_{z}^{f}+2}{N_{z}^{f}}} \Rightarrow \omega_{D}^{f}>\omega_{D}^{i}
$$

It can be seen that Debye frequency has somewhat greater value in film than in unbounded crystalline structure.

\section{THERMODYNAMICS OF PHONON FILMS}

Forasmuch as the properties of anisotropic structures are conditioned by the change of dispersion law, it is necessary to observe behavior of cer-

$$
\begin{aligned}
U_{f}(x)=\frac{3 N_{f}}{4 \pi^{2}} \frac{\Delta^{4}}{E_{0}^{3}} x^{2}\{ & {\left[Z_{2}\left(\frac{1}{x}\right)-\eta^{2} Z_{2}\left(\frac{\eta}{x}\right)+\eta^{2} \zeta^{2} Z_{2}\left(\frac{\eta \zeta}{x}\right)-\zeta^{2} Z_{2}\left(\frac{\zeta}{x}\right)\right]+} \\
+4 x & {\left[Z_{3}\left(\frac{1}{x}\right)-\eta Z_{3}\left(\frac{\eta}{x}\right)+\eta \zeta Z_{3}\left(\frac{\eta \zeta}{x}\right)-\zeta Z_{3}\left(\frac{\zeta}{x}\right)\right]+} \\
& \left.+6 x^{2}\left[Z_{4}\left(\frac{1}{x}\right)-Z_{4}\left(\frac{\eta}{x}\right)+Z_{4}\left(\frac{\eta \zeta}{x}\right)-Z_{4}\left(\frac{\zeta}{x}\right)\right]\right\},
\end{aligned}
$$

where the symbol $x$ is introduced for reduced temperature: $x=\theta / \Delta$.

For finding an expression for the thermal capacitance per a unit cell (here: per an atom), the standard definitional form is used: tain thermodynamic properties towards obtainment of better understanding about those properties.

Hence, when $k \rightarrow 0$ (in longwave approximation), energies of all three phonon branches have non-zero values, dispersion relation (8) can be used in a somewhat simplified form:

$E_{\vec{k}}=\sqrt{a^{2} k^{2} E_{0}^{2}+\Delta^{2}\left(k_{z}\right)}$;

$\Delta\left(k_{z}\right) \equiv E_{0} a k_{z} ; E_{0} \equiv \hbar \Omega$

It should be specifically emphasized that the verification of phonon dispersion law at very low values of $k$ is virtually impossible, so that the verification of existence of phonon gap appears in measurement of low temperature thermal capacitances in film and corresponding ideal structure.

The thermal capacitance is analyzed, whereby at first internal energy is calculated in terms of standard form [6,7]: $U_{f}=3 \sum_{k_{x}, k_{y}, k_{z}} E_{\vec{k}}\left[\mathrm{e}^{E_{\vec{k}} / \theta}-1\right]^{-1}$. After suitable

notations: $\quad \eta \equiv \sqrt{\frac{N_{z}^{2}}{3}+N_{z}+1} \quad$ and
$\zeta \equiv \sqrt{1+\left(\frac{N_{z}+2}{\pi} \sqrt[3]{6 \pi^{2}}\right)^{2}}$ and adequate operations, expression for internal energy has been obtained in form:
$C_{f}=\frac{1}{N_{f}} \frac{\partial U_{f}}{\partial T}=\frac{k_{\mathrm{B}}}{N_{f}} \frac{\partial U_{f}}{\partial \theta}=\frac{1}{\Delta} \frac{k_{\mathrm{B}}}{N_{f}} \frac{\partial U_{f}}{\partial x}$.

Based on that, we arrive at: 


$$
\begin{aligned}
C_{f}(x)=\frac{3 k_{\mathrm{B}}}{4 \pi^{2}}\left(\frac{\Delta}{E_{0}}\right)^{3}\{ & {\left[Z_{1}\left(\frac{1}{x}\right)-\eta^{3} Z_{1}\left(\frac{\eta}{x}\right)+\eta^{3} \zeta^{3} Z_{1}\left(\frac{\eta \zeta}{x}\right)-\zeta^{3} Z_{1}\left(\frac{\zeta}{x}\right)\right]+} \\
+ & 6 x\left[Z_{2}\left(\frac{1}{x}\right)-\eta^{2} Z_{2}\left(\frac{\eta}{x}\right)+\eta^{2} \zeta^{2} Z_{2}\left(\frac{\eta \zeta}{x}\right)-\zeta^{2} Z_{2}\left(\frac{\zeta}{x}\right)\right]+ \\
+ & 18 x^{2}\left[Z_{3}\left(\frac{1}{x}\right)-\eta Z_{3}\left(\frac{\eta}{x}\right)+\eta \zeta Z_{3}\left(\frac{\eta \zeta}{x}\right)-\zeta Z_{3}\left(\frac{\zeta}{x}\right)\right]+ \\
+ & \left.24 x^{3}\left[Z_{4}\left(\frac{1}{x}\right)-Z_{4}\left(\frac{\eta}{x}\right)+Z_{4}\left(\frac{\eta \zeta}{x}\right)-Z_{4}\left(\frac{\zeta}{x}\right)\right]\right\} .
\end{aligned}
$$

It is known that the phonon part in thermal capacitance of the system is described with cubic temperature dependence. By introducing nondimensional reduced temperature, this dependence amounts to: $C_{b}(x)=\frac{12}{5} \pi^{4} N_{i} k_{\mathrm{B}}\left(\frac{\Delta}{E_{D}}\right)^{3} x^{3}$. For comparison of these dependences, expressions (2.5) and (2.6) are divided by the constant: $C_{0}=\frac{k_{\mathrm{B}}}{2}\left(\frac{\Delta}{E_{D}}\right)^{3}$, whose dimension is equal to the dimension of thermal capacitance, and nondimensional properties are compared: $\boldsymbol{c}_{f / b} \equiv C_{f / b}(x) / C_{0}$. Fig.3 shows relative (nondimensional) thermal capacitances of bulk (b) and film-structure (f) subject to the relative temperature $x$, for $N_{z}=3$ (a), $N_{z}=8$ (b) and $N_{z}=48$ (c).
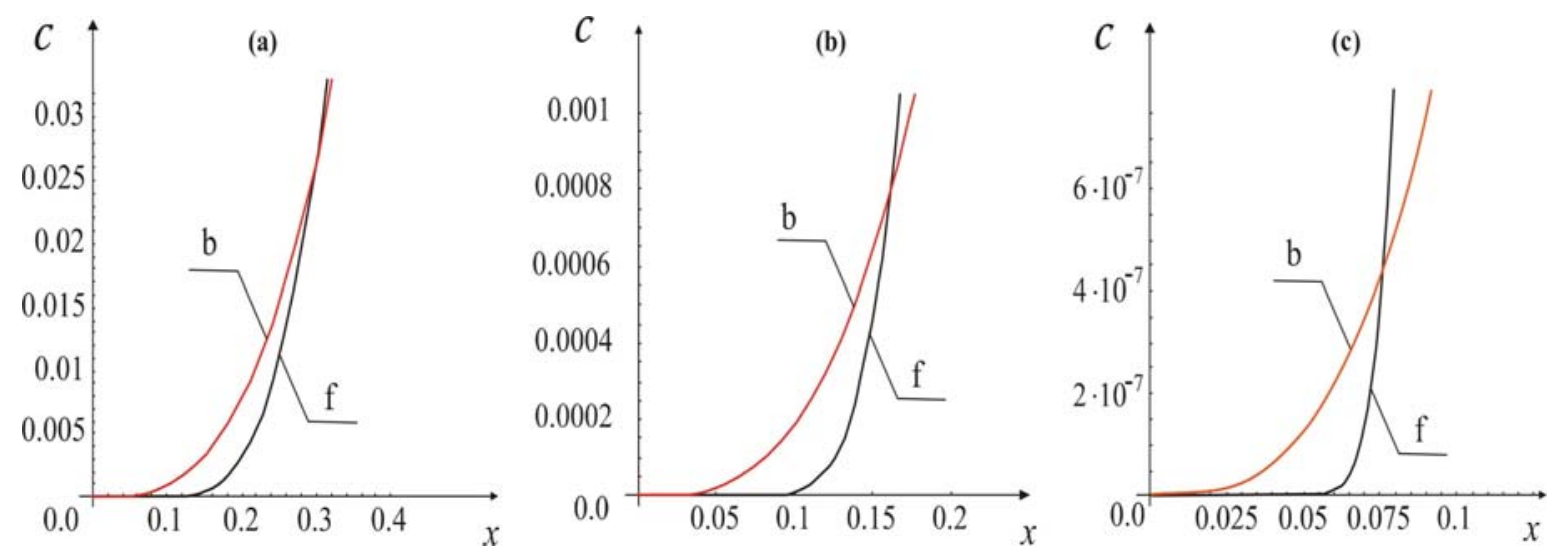

Figure 4. Low-temperature behavior of thermal capacity for bulk, ultrathin, thin and thicker film structures

It can be seen that in low-temperature region (Fig.4a) thermal capacitance of film is lower than that of massive specimens, whereas at the intermediate temperatures situation is reversed [5]. The intersection point of two curves at low temperatures is moving - with increase of film-thickness - towards lower temperatures (Fig. $4 \mathrm{a} \rightarrow \mathrm{c}$ ). Besides, it is noticeable that thermal capacitance of film with a decrease of temperature declines faster than that of the corresponding ideal structure, or slowly rises with the increase of temperature - to a certain upper temperature. Hence, in order to heat a film from certain lower to a certain upper temperature, it is necessary to use more thermal energy per mass unit than for heating the same quantity of corresponding (with the identical crystallographycal parameters) unbounded structure to the same temperature. It is in accordance with the fact that phonons in film have non-zero excitation energy.

\section{ANALYSIS OF THE RESULTS}

Based on the expression for phonon energy (8), minimum phonon energy is obtained for $k_{x}=k_{y}=0$ and $\mu=1$. This minimum value amounts to:

$$
E_{\min }=2 \hbar \Omega \sin ^{2} \frac{\pi}{2\left(N_{z}+2\right)}
$$


As it can be seen, the minimum phonon energy in the film is not equal to zero like in the ideal structure, and for a three-layer film $\left(N_{z}=2\right)$ it amounts to $2 \hbar \Omega \sin ^{2} \frac{\pi}{8}$ which, for Debye's temperatures of order $200 \mathrm{~K}$ gives the energy threshold for phonons which is of order $100 k_{B}$. This fact is very significant because it practically means that up to the temperature of $100 \mathrm{~K}$ the film behaves like an ideal structure on absolute zero, that is to say, it does not show any resistance to the movement of electrons. Therefore, ultrathin metal films can be expected to be high-temperature super-conductors.

With the mean square of movement in the film, the following film density was determined

$$
\rho=\frac{m}{a^{3}\left(1-3 \frac{<u_{\vec{n}}^{2}>}{a^{2}}\right)}
$$

because $<u_{\vec{n}}^{2}>$ depends on $n_{z}$, film density changes from layer to layer, and its values for ultrathin film are the highest in border layers, and lowest in the middle layer. Due to this, the density of the film as a whole cannot be determined, therefore we introduced a convention that the arithmetic mean of densities by layers is treated as density of the film as a whole.

Based on correlation functions, internal energy of the film was determined as a sum of mean values of Hamiltonian of film by layers [16-18]. It was possible to determine specific heat of the film only for film layers, therefore, according to the convention, the arithmetic mean of specific heats by layers was treated as specific heat of the entire film. By comparing specific heat of the film defined in such a way, with the specific heat of ideal structure, it was determined that at low temperatures specific film heat is by several orders of magnitude lower than the specific heat of ideal structure, that in the interval $(80,97) \mathrm{K}$ it is somewhat higher than the heat of the ideal structure, and that at temperatures higher than $97 \mathrm{~K}$ it becomes lower again.

The film heat conductivity, given with the following formula, has a similar behaviour:

$$
\lambda=D \cdot C_{V} \cdot \rho \text {, }
$$

whereby $D$ is a diffusion ratio. With regards to the ideal structure, the heat transfer ratio behaves similarly to specific heat, which means that at low temperatures it is by a few orders of magnitude lower than the heat ratio of the ideal structure, that in the interval of temperatures $(76,5-101,5) \mathrm{K}$ is insignificantly higher and that at temperatures higher than $101,5 \mathrm{~K}$ it is lower again than the heat conductivity ratio of ideal structure.
In Fig. 5 dependences of heat transfer ratio on temperature, respectively for film and ideal structure, are presented. A general conclusion derived from the comparison of specific heat and heat transfer ratio for film and the ideal structure is that the film has high thermal-insulation properties.

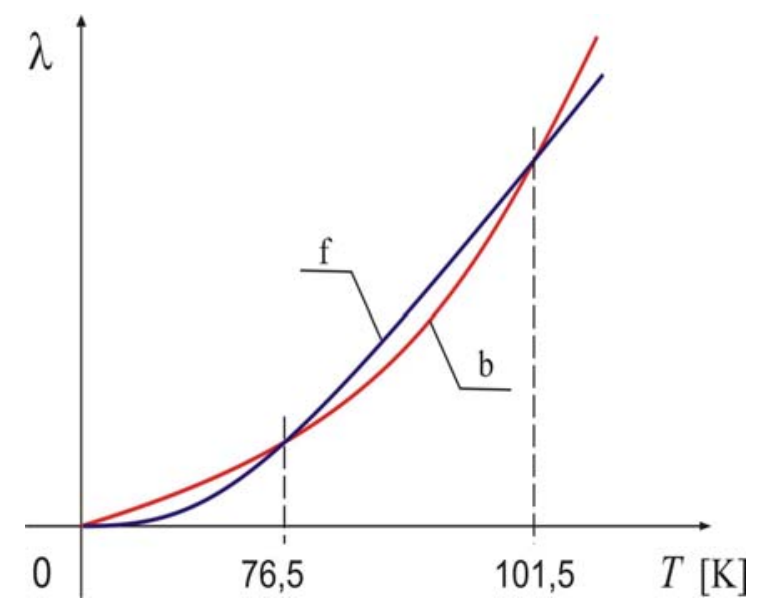

Figure 5. Heat transfer ratio

We will finally determine diffusion tensor of phonons which is, based on $[19,20]$, determined by the formula

$D_{\vec{n} \vec{m}}=\left|\lim _{\varepsilon \rightarrow 0} \int_{0}^{\infty} d t e^{-\varepsilon t} \frac{<p_{\vec{m}}(0) p_{\vec{n}}(t)>}{M^{2}}\right|$.

By using the correlation function derived from Green's function of double impulse type we find that the diffusion tensor of phonon is diagonal and that all of its diagonal elements are the same. The formula obtained for the diffusion tensor is as follows:

$D_{n_{x}, n_{y}, n_{z} ; m_{x}, m_{y}, m_{z}}=\frac{\hbar}{2 M} \delta_{n_{x}, m_{x}} \delta_{n_{y}, m_{y}} \delta_{n_{z}, m_{z}}$.

As it can be seen, the value of diagonal element in (23) $D=\frac{\hbar}{2 M}$, which represents the diffusion ratio, does not depend on temperature or on coordinates.

In phonon sub-system of ultrathin films, responsible for mechanical properties, the increased oscillations and forming of stationary waves occur, whereas thermal conductivity decreases. Due to an increase in phonon influence, their positive effect on the size of ion-phonon interaction can be expected, having in mind that a considerable part of thermal energy is spent for this increase. Based on that we can conclude that a response with regards to the mechanism of higher efficiency of ion transport could include positive influence of vibrations of crystal lattice of electrode coatings. Those vibrations have a 
sort of "reanimating" or "reviving" effect on ions, thus creating conditions for their more frequent and faster transfer. On the other hand, with their increased oscillating, phonons release the ions "captured" within and on electrodes, which, without the presence of coatings could never again be able to take part in transfer of electrical charge and energy between electrodes within Li-ion batteries. In that way, this system: electrodes with ultrathin coatings - has an effect to increase the efficacy of Li-ion conduction.

It is noteworthy that the lower the thickness of coating, the bigger the influence of phonons!

\section{CONCLUSION}

The paper outlines the results of research of behavior of phonon sub-system in ultrathin coatings that are laid on electrodes in Li-ion batteries and increase the efficacy of ion transport. It has been demonstrated that increased mechanical oscillating of crystal lattice occurs in ultrathin films, as well as the forming of standing waves, whereas the thermal capacitivity and conduction of the overall coating decreases. With their increased oscillating phonons release the ions "captured" in and on electrodes, which ions, without the presence of coatings would not be able any more to take part in transfer of charge and energy between the electrodes within Li-ion batteries. In this way, this system: electrodes with ultrathin coatings - influences an increase in efficiency of Liion conduction.

\section{REFERENCES}

[1] J. M. Tarascon, M. Armand, Issues and challenges facing rechargeable lithium batteries, Nature 414 (2001) 359-367.

[2] P. L. Taberna, S. Mitra, P. Poizot, P. Simon \& J. M. Tarascon, High rate capabilities $\mathrm{Fe}_{3} \mathrm{O}_{4}$-based $\mathrm{Cu}$ nano-architectured electrodes for lithium-ion battery applications, Nature Materials 5 (2006) 567-573.

[3] S. Pejovnik, R. Dominko, M. Bele, M. Gaberscek and J. Jamnik, Electrochemical binding and wiring in battery materials, Journal of Power Sources, 184-2 (2008) 593-597.

[4] J. Hong, Ch. Wang, U. Kasavajjula, Kinetic behavior of LiFeMgPO4 cathode material for Li-ion batteries, Journal of Power Sources 162 (2006) 1289-1296.
[5] Y. S. Jung, A. S. Cavanagh, A. C. Dillon, M. D. Groner, S. M. George, and Se-Hee Leea, Enhanced Stability of $\mathrm{LiCoO}_{2}$ Cathodes in LithiumIon Batteries Using Surface Modification by Atomic Layer Deposition, Journal of The Electrochemical Society, 157-1 (2010) A75-A81.

[6] D. Popov, S. K. Jaćimovski, B. S. Tošić, J. P. Šetrajčić, Kinetics of thin films mechanical oscillations, Physica A 317 (2003) 129-139.

[7] B. S. Tošić, J. P. Šetrajčić, D. Lj. Mirjanić, Z. V. Bundalo, Low-Temperature Properties of Thin Films, Physica A, 184 (1992) 354-366.

[8] S. G. Davison and M. Steslicka, Basic Theory of Surface States, Clarendon, Oxford (1996).

[9] M. Prutton, Introduction to Surface Physics, Clarendon, Oxfod (1995).

[10] M. Tkach, V. Holovatsky, O. Voitsekhivska, Electron and hole quasistationary states in opened cylindrical quantum wire, Physica E, 11 (2001) 17-26.

[11] V. M. Golovach, G. G. Zegrya, A. M. Makhanets, I. V. Pronishin, N. V. Tkach, Electron and hole spectra in a superlattice of cylindrical quantum wires, Semiconductors, vol.33/5 (1999) 564-568.

[12] J. M. Wesselinowa, On the theory of thin ferroelectric films, Phys.Stat.Sol. (b), 223 (2001) 737.

[13] J. M. Wesselinowa, Electric field dependence of phase transitions in ferroelectric thin films, Phys.Stat.Sol. (b), 229 (2002) 1329.

[14] B. S. Tošić, Statisticka fizika, PMF, Novi Sad (1978).

[15] S. Doniach, E. H. Sondheimer, Green's Functions for Solid State Physicists, Imperial College Press, London (1999).

[16] C. Kittel, Introduction to Solid State Physics, Wiley, New York (1986).

[17] H. Ibach, H. Lüth, Solid-State Physis, An Introduction to Principles of Material Science $3^{\text {rd }}$ edition, Springer, Berlin / Heidelberg / New York (2003).

[18] G. Strobl, Condensed Matter Physics, Crystals, Liquid Crystals and Polymers, Springer, Berlin/Heidelberg/New York (2004).

[19] V. M. Agranovich and M. D. Galanin, Migration of Electron Energy Excitations in Condensed Matter, Nauka, Moscow (1978).

[20] D. Lj. Mirjanić, J. P. Šetrajčić, S. S. Pelemiš and S. Armaković, Ultrathin Coating of Electrodes and Influence of Phonons on an Increase of Conductivity of Li-Ion Batteries, Contemporary Materials II-1 (2011) 45-50. 
D. Lj. Mirjanić, et al., Increase of mobility of ions in Li-ion batteries ...

$\sin$

\section{ПОВЕЋАЮЕ МОБИЛНОСТИ ЈОНА У Li-ЈОНСКИМ БАТЕРИЈАМА УЛТРАТАНКИМ ФОНОНСКИМ ПРЕВЛАКАМА ЕЛЕКТРОДА}

Сажетак: У раду су представљени резултати истраживања понашања фононског подсистема у ултратанким превлакама какве се наносе на електроде у Li-joнским батеријама и повећавају ефикасност јонског транспорта. Методом Гринових функција показано је да у ултратанким филмовима долази до појаве појачаног механичког осциловања кристалне решетке и формирања стојећих таласа, а смањења термичке капацитивности и проводљивости цијеле превлаке. Својим појачаним осциловањем фонони ослобађају у и на електродама заробљене јоне и тако утичу на повећање ефикасности јонског провођења.

Кључне ријечи: јонска проводност, Li-јонске батерије, ултратанки филмови, фонони, топлотна капацитивност.

$\cos 80$ 